\title{
Prevalence of porcine cysticercosis in Nagaon, Morigaon and Karbianglong district of Assam, India
}

\author{
S Borkataki, S Islam, MR Borkakati, P Goswami*, DK Deka \\ Department of Parasitology, College of Veterinary Sciences, \\ Assam Agricultural University, Khanapara, Guwahati 781 022, Assam, India \\ * Corresponding author email: drpanku@sify.com \\ Received: 04-07-2011, Accepted: 19-08-2011, Published Online: 13-12-2011 \\ doi: $10.5455 /$ vetworld.2012.86-90
}

\begin{abstract}
Prevalence of Porcine Cysticercosis in three districts of Assam was studied for a period of one year from March 2002 to February 2003. Except certain geographical region of Assam, many districts of this state have yet remained unexplored for this important zoonotic disease, let along the following three districts i.e. Nagaon, Morigaon and KarbiAnglong. Monthly visit to the market places were made in different localities of the three districts. Prevalence of cysticercosis according to age, sex, breed of carcasses and seasonal occurrence were studied. The whole period of observation was divided in to four seasons as per Indian Meteorological Department as pre-monsoon, monsoon, post- monsoon and winter. A total of 978 pigs were examined, out of which 93 pigs $(9.50 \%)$ were found to be positive for infection. District wise highest $(13.70 \%)$ prevalence was found in KarbiAnglong and lowest (7.55\%) in Nagaon district. Age wise prevalence study showed highest $(11.41 \%)$ in the age group of 7-12 months and lowest (7.60\%) in the age group 19-24 months. Prevalence of C. cellulosae infection in male and female was 9.15 and 10.39 percent respectively. Breed wise prevalence was found more in cross bred $(12.53 \%)$ than in local breed $(7.49 \%)$. Overall seasonal prevalence was highest during pre-monsoon (10.93\%) and lowest $(7.82 \%)$ during monsoon season. Though there were variation in the rate of prevalence of porcine cysticercosis based on age, sex, breed and seasons. The disease was found to exist in the study area throughout the year that ranged from 5.71 to 14.06 percent.
\end{abstract}

Key Words: Zoonosis, Cysticercosis, Porcine

\section{To cite this article:}

Borkataki S, Islam S, Borkakati MR, Goswami P and Deka DK (2012): Prevalence of porcine cysticercosis in Assam, India, Vet. World 5 (2): 86-90, doi: 10.5455/vetworld.2012.86-90.

\section{I ntroduction}

Porcine cysticercosis due to Cysticercus cellulosae is a disease caused by larval stage of Taenia solium. Pig act as intermediate host for perpetuate the life cycle of $C$. cellulosae. Human is the only natural host of adult stage of $T$. solium which causes taeniasis, a serious parasitic zoonosis (WHO, 1979). Cysticercosis in humans occurs due to the ingestion of this tape worm eggs, either from external sources or from the person's own feces. The human has then become an accidental and "dead-end" intermediate host (that is, the infection can not progress any further.(Markell et. al. 1999). Pigs, which are the "normal" intermediate host for this parasite, get infected with cysticerci when they ingest human feces.
Pig rearing is common in Assam. Pig rearing practices in Assam are mostly semi-intensive and free ranging sytem.

Cysticercosis due to C. cellulosae in pig is acquired due to unhygienic feed or water intake by this animal along with the viable eggs of $T$. solium. In pigs, cysts are distributed in the striated muscles like heart, tongue and skeletal muscle like forearm. The cysts were also found in liver, lung, spleen, eye, conjunctiva and nervous system of pigs, which remain viable for long time. Presence of cyst in the tissue is responsible for the condemnation of meat, thus economic losses to the pig producer. The prevalence of this metacestode is therefore taken considerable importance and a study was conducted to explore the incidence of this parasite in market pork 
brought for human consumption.

\section{Materials and Methods}

Epidemiological studies of porcine cysticercosis was conducted in Nagaon, Morigaon and Karbianglong district of Assam for a period of one year starting from the month of March 2002 to February 2003. The study areas were a representative of urban, semi-urban and rural district of Assam, the northeastern part of India. Good numbers of pork were marketed in these districts of the state. Monthly visit to the market places were made in different localities of the three districts of Assam. Pig carcasses brought for human consumption in the market were examined as per the method of Thronton and Gracy (1974) for presence of $C$. cellulosae. Age, sex and breed of the carcasses were recorded. Animal were divided in to different age groups i.e. 1-6, 7-12, 13-18 and 19-24 months of age. Seasonal prevalence of porcine cysticercosis was also recorded. The whole period of observation were divided in to four seasons i.e. pre-monsoon (March, April and May), monsoon (June, July, August and September), post-monsoon (October and November) and winter season (December, January and February).

\section{Results}

A total of 978 pigs were examined for cysticercosis, out of which 93(9.5\%) were found to be positive. A total of 318 numbers of pig carcasses were examined at different localities of Nagaon districts for the presence of C. cellulosae. Out of which $24(7.55 \%)$ were found to be positive. Highest infection (11.76\%) was found in the age group of 1-6 months and lowest $(4.87 \%)$ in $13-18$ months of age. Percentage of infection in male and female was 7.86 and 5.26 respectively. Breed wise prevalence study showed a total of 282 local pig examined, out of which $21(7.44 \%)$ were found positive and out of 36 cross bred pig examined, $3(8.33 \%)$ were found positive. In the same district, highest infection (10.76\%) was found during the premonsoon season.

In Morigaon district, a total of 390 pigs was examined, out of which $32(8.2 \%)$ were found to be positive. The highest infection $8.69 \%$ (12 positive out of 138,) found in the age group 7-12 months and the lowest infection 6.89\% in 1-6 months (2 out of 29). Percentage of infection in male pig was found $8.24 \%$ (24 out of 291) and in female $8.08 \%$ ( 8 out of 99 female pigs). Breed wise prevalence study showed out of 215 crossbred pigs examined, $21(9.76 \%)$ and out of 175 local pigs examined, 11(6.28\%). Prevalence of infection was highest $10.11 \%$ during the premonsoon season (out of 89,9 were found to be positive) and lowest infection $6.92 \%$ during the monsoon season (out of 130, 9 were found to be positive).

In KarbiAnglong district, prevalence of Cysticercosis was studied on 270 numbers of pigs, out of which $37(13.7 \%$ ) were found to be positive. Age wise prevalence showed highest infection (16.00\%) was found in the age group of 13-18 months (Out of 50 pigs examined, 8 were found to be positive). Lowest infection recorded $8.33 \%$ in $19-24$ months of age i.e. out of 60 pigs examined 5 were found to be positive. Examination of 128 male and 142 female pigs showed $18(14.06 \%)$ and $19(13.38 \%)$ nos positive for cysticercosis. Breed wise prevalence study showed a total of 130 local pigs were examined, out of which 12(9.23\%) and out of 140 crossbred animals examined, 25(17.85\%). Seasonal prevalence of infection showed highest infection $21.62 \%$ was found during the winter season i.e. out of 37 pigs examined, 8 were found to be positive. Lowest infection $11.11 \%$ was found during monsoon season i.e. out of 99 pigs examined, 11 were found to be positive.

Overall age wise prevalence in different age group irrespective of 3 districts has been summarized in Table-1. Highest infection $(11.41 \%)$ was found in the age group of 7-12 months i.e. out of 403 pigs examined 46 were found to be positive and lowest infection $7.60 \%$ in the age group19-24 months of age i.e. out of 171 pigs examined, 13 were found to be positive. Overall sex wise prevalence irrespective of 3 districts has been summarized in Table-2. Out of total 699 male pigs examined, $64(9.15 \%)$ found to be positive and out of a total 279 female pigs examined, 29(10.39\%) were found to be positive. Overall breed wise prevalence irrespective of 3 
Prevalence of porcine cysticercosis in Nagaon, Morigaon and Karbianglong district of Assam, India

Table-1: Age wise overall prevalence of C.cellulosae in pigs from March 2002 to February 2003

\begin{tabular}{lccccccc}
\hline $\begin{array}{l}\text { Age Gr. } \\
\text { (Months) }\end{array}$ & \multicolumn{2}{c}{$\begin{array}{c}\text { Nagaon } \\
\text { No. animal No.positive }\end{array}$} & $\begin{array}{c}\text { Morigaon animal } \\
\text { No. positive }\end{array}$ & $\begin{array}{c}\text { KarbiAnglong } \\
\text { No. animal }\end{array}$ & \multicolumn{2}{c}{ No. positive } & \multicolumn{2}{c}{ No. animal } \\
No. positive
\end{tabular}

*Figure in the parenthesis indicate percentage

Table-2: Sex wise overall prevalence of C.cellulosae in pigs from March2002 to February 2003

\begin{tabular}{lccccccc}
\hline $\begin{array}{l}\text { Sex } \\
\text { (Months) }\end{array}$ & \multicolumn{2}{c}{$\begin{array}{c}\text { Nagaon } \\
\text { No. animal }\end{array}$} & \multicolumn{2}{c}{ Morigaon } & \multicolumn{2}{c}{ KarbiAnglong } & \multicolumn{2}{c}{ Total } \\
Male & 280 & $22(7.85)$ & 29 & $24(82.75)$ & 128 & $18(14.06)$ & 699 \\
Female & 38 & $2(5.26)$ & 99 & $19(19.19)$ & 142 & $19(13.38)$ & 279 \\
\hline
\end{tabular}

* Figure in the parenthesis indicate percentage

Table-3: Breed wise overall prevalence of C. cellulosae in pigs from March 2002 to February 2003

\begin{tabular}{lccccccc}
\hline $\begin{array}{l}\text { Breed } \\
\text { (Months) }\end{array}$ & \multicolumn{2}{c}{ Nagaon } & \multicolumn{2}{c}{ Morigaon } & \multicolumn{2}{c}{ KarbiAnglong } & \multicolumn{2}{c}{ Total } \\
No. animal No.positive & No. animal & No. positive & No. animal & No. positive & No. animal & No. positive \\
\hline Local & 282 & $21(7.44)$ & 175 & $11(6.28)$ & 130 & $12(9.23)$ & 587 \\
Crossbred & 36 & $3(8.33)$ & 215 & $21(9.76)$ & 140 & $25(17.85)$ & 391 \\
\hline
\end{tabular}

*Figure in the parenthesis indicate percentage

Table-4: Overall seasonal prevalence of C.cellulosae in pigs from March 2002 to February 2003

\begin{tabular}{|c|c|c|c|c|c|c|c|c|}
\hline \multirow{2}{*}{$\begin{array}{l}\text { Season } \\
\text { (Months) }\end{array}$} & \multirow{2}{*}{$\begin{array}{r}\text { Naga } \\
\text { No. animal }\end{array}$} & \multirow{2}{*}{$\begin{array}{l}\text { Ion } \\
\text { No.positive }\end{array}$} & \multirow{2}{*}{\multicolumn{2}{|c|}{$\begin{array}{c}\text { Morigaon } \\
\text { No. animal No. positive }\end{array}$}} & \multicolumn{2}{|c|}{ KarbiAnglong } & \multicolumn{2}{|c|}{ Total } \\
\hline & & & & & No. animal & No. positive & No. animal & No. positive \\
\hline Premonsoon & 65 & $7(10.76)$ & 89 & $9(10.11)$ & 38 & $5(13.15)$ & 192 & $21(10.93)$ \\
\hline Postmonsoon & 73 & $6(8.21)$ & 87 & 899.19) & 96 & $13(13.54)$ & 256 & $27(10.54)$ \\
\hline Winter & 64 & $4(6.25)$ & 84 & $6(7.14)$ & 37 & $8(21.62)$ & 185 & $18(9.72)^{\prime}$ \\
\hline
\end{tabular}

*Figure in the parenthesis indicate percentage

districts has been summarized in Table-3. A total of 587 local pigs examined, 44(7.49\%) were found to be positive. A total of 391 crossbred pigs examined, 49 (12.53\%) were found to be positive. Overall seasonal prevalence irrespective of 3 districts has been summarized in Table-4. Highest infection (10.93\%) was found in pre monsoon season i.e. out of a total 192 pigs examined, 21 were found to be positive and lowest $(7.82 \%)$ was found in winter season i.e. out of a total 185 pigs examined ,18 were found to be positive.

\section{Discussion}

Present study was conducted to record the prevalence of C.cellulosae in pigs in 3 districts of Assam i.e. Nagaon, Morigaon and Karbi Anglong from March 2002 to February 2003. The study revealed overall $9.50 \%$ prevalence of cysticercosis in pigs. Previously Sarma (1977) recorded 6.64\% cysticercosis from greater Guwahati of Assam. Deka et.al (1985) and Plain (1991) recorded $20.80 \%$ and $11.90 \%$ infection from North Eastern region of Assam respectively. Deka et.al. (1995) reported the disease is common in pigs in Lakshmpur district of Assam. ICAR Annual Progress Report (2000-2001 and 2001-2002) reported incidence of porcine cysticercosis $3.66 \%$ and $3.99 \%$ respectively from 8 districts of Assam including Nagaon and KarbiAnglong district. The result of the present study was in corroboration with the findings of other workers 
as referred above and establishes the fact that, the present study areas were endemic for porcine cysticercosis. In the present study age wise prevalence of porcine cysticercosis was found to highest $(11.41 \%)$ in the age group of 7-12 months and lowest $(7.60 \%$ ) in 19-24 months of age. Aluja et. al. (1998) recorded the earliest age of piglets who get infected in rural community in Mexico was from 2-4 weeks of age.

Pigs reared in the present study area were let loose and had free access to contaminated areas from where they acquired the infection. Therefore the finding implies that there was a continuous level of infection in environ-ment in which the animals are regularly exposed to infection. Aluja and Vargas (1988) classified histological lesions according to the severity of tissue inflammatory response, larval degeneration and replacement by scar tissue in porcine cysticercosis. They were of the opinion that, greater number of degenerated larvae might occur in older pigs, many of which are acquired during early stage of life. In the present study, it was rather difficult to ascertain at which age the infection was picked up to what proportion the cysts were degenerated in older age in natural cases. In present study areas maximum number of animals was brought to the market within the age group of 7-12 months of age, therefore these age groups considered as high-risk group of animal in comparison to other three groups which may give infection to human being. Further young pigs are preferred more by the consumers, which were found to be more delicious and used for small community gatherings and festivals that might act as source of infection to human being. In the present study, sex wise overall prevalence of porcine cysticercosis was found to be higher in females $(10.39 \%)$ than in males $(9.15 \%)$. Earlier, Deka(1989), Plain(1991) and DevSarma (1999) also recorded similar result, which was in agreement with the present findings.

Higher prevalence in females in present study might be due to the natural feeding behaviors of females with their litters who use to loiter in and around human habitats in search of garbage and generally avoid conflict with their aggressive male counterparts. Similar observations were also made by Aluja et. al.(1998). Breed wise overall prevalence of porcine cysticercosis in the present study was found to be more in cross bred $(12.53 \%)$ than in local bred (7.49\%) pigs.(Table3). Previously Pramanik et.al.(1985) and Deka and Gaur (1990) could also recorded higher infection in crossbred than in indigenous animals.

This finding might be due to breed predisposition, which requires further detail studies. In Morigaon district, it was noted that good proportion of crossbred pigs were regularly brought to the market from outside of the state of NE-region who might harbouring the infection and also contributing to the already existing disease situation in the study area. This contention could be substantiated by the high prevalence rate of porcine cysticercosis in the contiguous states (Kumar and Gaur 1994).In the present study, overall seasonal record was found highest infection during pre-monsoon season (10.935) and lowest (7.82\%) during monsoon season. (Table - 4) which was not agreement with the finding of Deka (1989) who recorded highest infection in Autumn (5.10\%) and lowest $(2.65 \%)$ in winter, but was in agreement with D,Souza (1998) who recorded higher infection during the summer (March to May)than the winter season (January to February). This finding might be due to geographical variation in all three study areas under reference.

It was interesting to note that, though there was fluctuation of infection in all the three different districts of the study area, it showed that, the entire study area was highly endemic for porcine cysticercosis and may be sources of infection to human taeniasis in local population.

\section{Acknowledgements}

Authors are highly thankful to Dean, College of Veterinary Sciences, Khanapara, Guwahati for providing necessary facilities to carry out the study. The work was supported in the form of financial grant by Indian Council of Agricultural Research, New Delhi under the sponsored Research Project.

\section{Conflict of interest}

Authors declare that they have no conflict of interest. 
Prevalence of porcine cysticercosis in Nagaon, Morigaon and Karbianglong district of Assam, India

\section{References}

1. Aluja, A.S. de., Martinez, J. J., Villalobos, A.N.M. (1998). Tania solium cysticercosis in young pigs: age at first infection and histological characteristics. Vet. Parasitol., 76, 71-79.

2. Aluja, A.S. de, Vargas, G. (1988). The histopathology of Porcine Cysticercosis. Vet. Parasitol. , 28 (1/2), 65-77.

3. D,Souza,P.E. (1998). Studies on porcine cysticercosis with special reference to serodiagnosis. J.Vet. Parasitol 12 (1):64.

4. Deka, D. (1989). Epidemiology and immunodiagnosis of certain common larval cestodes of domestic animals. PhD Thesis submitted to G.B. Pant university of Agriculture and Tech., Pantnagar, India.

5. Deka,D.K., Borkakoty, M.R., Lahkar, B.C. (1985). Cysticercosis in domestic animals in North Eastern region of India. Indian. J. Parasitol., 9(1):83-85.

6. Deka, D.K., Gaur, S.N.S. (1990). Tania solium cysticercosis in pigs in western parts of Uttar Pradesh. J.Vet. Parasitol ., 4 (1), 59-63.

7. Deka, D.K., Choudhury,S., Chakraborty, A. (1995). Parasites of domestic animals and birds in Lakhimpur (Assam) J.Vet.Parasitol., 9 (1), 21-25.

8. DevSarma, M.K. (1999). Some aspects of hydatidosis and other common larval cestodes of domestic animals. M.V.Sc. Thesis submitted to A.A.U., Khanapara, Guwahati-22, Assam.

9. Markell EK, John DT, Krotoski WA. (1999). Medical Parasitology 8th Edn. Pennsylvania: Saunders.

10. Molinari,J.L., Tato, P., Sepulveda, J. (1992). Twinning in metacestodes of Taenia solium. J. Parasitol. 78(5), 920.
11. Pramanik, A.K., Bhattacharyya, H.M., Sengupta, D.N. (1985). Occurance of Cysticercus cellulosae in slaughtered pigs in Calcutta and its public health significance. Indian. J. Anim. Hlth 24 : 143-146.

12. Kumar,D., Gaur, S.N.S. (1994). Taenia solium cysticercosis in pigs. Helm. Abstr., 63(10), 365-383.

13. Plain, B. (1991). Studies on the incidence of cysticercosis in pig and cattle with special reference to taeniasis in human being in Assam and Meghalaya. M.V.Sc. Thesis submitted to the Assam Agricultural University.

14. ICAR Progress Report (2000-2001).Studies on Hydatidosis /Cysticercosis in different animals of N.E. Region. Dept. Parasitol.,C.V.Sc, A.A.U., Khanapara, Guwahati-22, Assam.

15. ICAR Progress Report (2001-2002).Studies on Hydatidosis /Cysticercosis in different animals of N.E. Region . Dept. Parasitol.,C.V.Sc, A.A.U., Khanapara, Guwahati-22, Assam.

16. Sarma,G.C. (1977) Studies on incidence of human taeniasis and animal cysticercosis in Greater Guwahati area of Assam. M.V. PH. Thesis, University of Culcutta, West Bengal.

17. Thornton, H,;Gracey, J.F. (1974). Textbook of Meat Hygiene. 6 Edition. Bailliere and Tindall, London.

18. Vargas,M.G.D., Saldierna, U., NavarroFlerro, R., Acevedo Hernandez, A., Flisser, de. M,A., Aluja, A. S. de (1986). Localization of Taenia solium cysticercosis in different muscle region of swine and its significance in meat inspection. Veterinaria Mexico, 17 (4):275-279.

19. World Health Organization (1979). Parasitic Zoonosis, Report of a WHO expert committee with the participation of FAO Technical report series. 637. 